\title{
Changes of Sleep Architecture, Spectral Composition of Sleep EEG, the Nocturnal Secretion of Cortisol, ACTH, GH, Prolactin, Melatonin, Ghrelin, and Leptin, and the DEX-CRH Test in Depressed Patients during Treatment with Mirtazapine
}

\author{
Dagmar A Schmid', Adam Wichniak', Manfred Uhr', Marcus Ising', Hans Brunner', Katja Held', \\ Jutta C Weikel', Annette Sonntag' and Axel Steiger*,', \\ 'Max Planck Institute of Psychiatry, Munich, Germany
}

\begin{abstract}
The noradrenergic and specific serotoninergic antidepressant mirtazapine improves sleep, modulates hormone secretion including blunting of hypothalamic-pituitary-adrenocortical (HPA) activity, and may prompt increased appetite and weight gain. The simultaneous investigation of sleep electroencephalogram (EEG) and hormone secretion during antidepressive treatment helps to further elucidate these effects. We examined sleep EEG (for later conventional and quantitative analyses) and the nocturnal concentrations of cortisol, adrenocorticotropin $(\mathrm{ACTH})$, growth hormone $(\mathrm{GH})$, prolactin, melatonin and the key factors of energy balance, ghrelin, and leptin before and after 28 days of treatment of depressed patients (seven women, three men, mean age $39.9 \pm 4.2$ years) with mirtazapine. In addition, a sleep EEG was recorded at day 2 and the dexamethasone-corticotropin-releasing hormone (DEX-CRH) test was performed to assess HPA activity at days -3 and 26. Psychometry and mirtazapine plasma concentrations were measured weekly. Already at day 2 , sleep continuity was improved. This effect persisted at day 28 , when slow-wave sleep, low-delta, theta and alpha activity, leptin and (0300-0700) melatonin increased, and cortisol and ghrelin decreased. ACTH and prolactin remained unchanged. The first two specimens of $\mathrm{GH}$ collected after the start of quantitative EEG analysis were reduced at day 28. The DEX-CRH test showed, at day 26, a blunting of the overshoot of ACTH and cortisol found at day -3 . The Hamilton Depression score decreased from $32.1 \pm 7.3$ to $15.5 \pm 6.7$ between days $-\mathrm{I}$ and 28 . A weight gain of approximately $3 \mathrm{~kg}$ was observed. This unique profile of changes is compatible with the action of mirtazapine at 5-HT-2 receptors, at presynaptic adrenergic alpha 2 receptors, at the HPA system, and on ghrelin and leptin. Neuropsychopharmacology (2006) 3 I, 832-844. doi: I 0.1038/sj.npp. I 300923; published online 19 October 2005
\end{abstract}

Keywords: mirtazapine; sleep; HPA system; ghrelin; leptin; depression

\section{INTRODUCTION}

Several reports showed that the noradrenergic and specific serotoninergic antidepressant (NaSSA) mirtazapine improves sleep, blunts the hormones of the hypothalamopituitary-adrenocortical (HPA) system, and may prompt increases of appetite and weight (De Boer, 1995; Laakmann et al, 1999, 2004; Aslan et al, 2002; Kraus et al, 2002; Schüle et al, 2002b). There is no study so far that addresses all these variables. Here, we report a longitudinal sleep-endocrine investigation on the changes of sleep electroencephalogram (EEG), sleep-associated hormone secretion including

*Correspondence: Dr A Steiger, Max Planck Institute of Psychiatry, Kraepelinstrasse 10, 80804 Munich, Germany, Tel: + 498930622 236, Fax: + 498930622 552, E-mail: steiger@mpipsykl.mpg.de

Received 13 April 2005; revised 21 July 2005; accepted 30 August 2005

Online publication: I September 2005 at http://www.acnp.org/citations/ Npp090 $05050243 /$ default.pdf melatonin and the endogenous factors of energy balance, ghrelin, and leptin, and assessment of HPA activity by the dexamethasone-corticotropin-releasing hormone (DEX$\mathrm{CRH})$ test and psychometry during treatment of patients with depression with mirtazapine.

Sleep-EEG studies in rats showed that a lower dose of mirtazapine prompted increases of slow-wave sleep (SWS) and decreases of wakefulness, whereas a higher dose prompted suppression of rapid-eye-movement (REM) sleep and increases of SWS (Schittecatte et al, 2002a). In young normal male subjects after $30 \mathrm{mg}$ of the substance given before bedtime sleep, stages awake and 1 decreased and one component of SWS, stage 3, increased (Ruigt et al, 1990). Similar results were derived from a study in young normal female and male subjects, who received after a baseline investigation, randomly either placebo or $30 \mathrm{mg}$ mirtazapine. After the substance, the sleep efficiency index and SWS increased, while the number of awakenings and the time spent in stages awake and 1 decreased (Aslan et al, 
2002). Three studies have examined the effects of mirtazapine on sleep in patients with depression so far. In a pilot study, six patients received $15 \mathrm{mg}$ mirtazapine during the first week and $30 \mathrm{mg}$ of the substance during the second week. When compared to baseline, sleep latency decreased and total sleep time and sleep efficiency increased during week 1 with similar results in week 2 (Winokur et al, 2000). In a larger sample, Schittecatte et al (2002a) found more distinct sleep-improving effects of mirtazapine. Already after 2 days administration of $15 \mathrm{mg}$, total sleep time, sleep efficiency index, and time spent in stage 2, REM, and SWS increased, whereas sleep latency and stage awake decreased. These effects persisted after 5 weeks of treatment with a maximum dosage of $45 \pm 11.8 \mathrm{mg}$. Finally, patients with major depression and insomnia were randomly assigned to either fluoxetine (20-40 mg/day) or mirtazapine (15-45 mg/ day) treatment for an 8-week trial (Winokur et al, 2003). Improvements in sleep latency, sleep efficiency index, and intermittent wakefulness occurred after 2 weeks of mirtazapine treatment. Continued improvement in these variables was observed throughout the remaining study period. After fluoxetine, sleep continuity variables remained unchanged, whereas the time in stage 1 sleep and REM latency increased between baseline and week 8 . All these studies showed an improvement of sleep quality after mirtazapine. Data on quantitative sleep-EEG (qEEG) analysis are not available so far. Melatonin is related to sleep promotion and melatonin levels are blunted in patients with depression (Miles and Philbrick, 1988). Interestingly, after mirtazapine, nocturnal melatonin levels increased in normal controls (Palazidou et al, 1989). The influence of mirtazapine on melatonin in depressed patients is unknown so far.

A series of studies by Laakmann and co-workers showed a blunting of HPA activity after mirtazapine in normal controls and depressed patients. Oral administration of $15 \mathrm{mg}$ mirtazapine in young normal male controls in the morning prompted a decrease of cortisol and adrenocorticotropin $(\mathrm{ACTH})$ plasma concentrations and a decrease of urinary free cortisol excretion, whereas growth hormone $(\mathrm{GH})$ and prolactin levels remained unchanged (Laakmann et al, 1999; Schüle et al, 2002b). These findings were confirmed in another report except for the decrease of prolactin secretion (Schüle et al, 2002a). In patients with depression, salivary cortisol concentrations were decreased already after 1 day of mirtazapine treatment at a dose of $30 \mathrm{mg}$. During a 3-week trial, this change did not differ in responders and nonresponders (Laakmann et al, 2004). Similarly, Schüle et al (2003) found that mirtazapine significantly reduced the overshoot of cortisol and ACTH during the DEX-CRH test at baseline after 1 week of treatment of depression by mirtazapine. This effect did not differ significantly between responders and nonresponders of the 5-week trial. These observations are of particular interest because HPA overactivity plays a key role in the pathophysiology of affective disorders (Nemeroff, 1996; Holsboer, 2000) and normalization of HPA activity was hypothesized to be the common mechanism of various antidepressants (Holsboer, 2003).

Weight loss is a frequent symptom of depression. Successful antidepressive therapy is accompanied by normalization of body weight. On the other hand, weight gain after antidepressants may override this beneficial effect and induce obesity as an unwanted side effect. Normalization of body weight and unwanted weight gain belong to the benefits and sequelae of treatment with mirtazapine (Nutt, 2002). Leptin morning levels were shown to increase during antidepressive treatment with mirtazapine (Kraus et al, 2002). Leptin is thought to participate in the energy balance as a major anorexigenic factor (Bates and Myers, 2003). Nocturnal leptin levels were elevated in drug-free patients with depression (Antonijevic et al, 1998; Rubin et al, 2002). Ghrelin was hypothesized to be the counterpart of leptin in the regulation of body weight (Horvath et al, 2001). This endogenous ligand of the GH-secretagogue receptor was isolated from the stomach, hypothalamus, and other organs of rats and humans (Kojima et al, 1999). It enhances food intake in rodents (Tschöp et al, 2000; Wren et al, 2001b) and humans (Wren et al, 2001a), appetite (Wren et al, 2001a; Schmid et al, 2005) in humans, and body weight in rodents (Tschöp et al, 2000). During sleep, ghrelin (Dzaja et al, 2004) and leptin (Antonijevic et al, 1998) were reported to increase. After a 6-month treatment with olanzapine, ghrelin plasma morning levels and body fat percentage increased in patients with schizophrenia, whereas their weight and body mass index (BMI) remained unchanged (Murashita et al, 2005). On the other hand, ghrelin levels in patients with schizophrenia who were under stable doses of olanzapine or risperidone for at least 4 weeks were lower than in normal controls, whereas BMI did not differ between groups (Togo et al, 2004). The effect of treatment with antidepressants, including mirtazapine, on ghrelin levels is unknown so far.

Sleep is a time of distinct activity in various endocrine systems. During sleep, neurobiological activity in patients can be studied for several hours free from disturbances by environmental factors. The simultaneous investigation of sleep EEG and sleep-related hormone secretion was shown to be a useful tool to characterize the neurobiological profile of central nervous system (CNS)-active drugs, including antidepressants (Steiger et al, 1993; Sonntag et al, 1996; Künzel et al, 2005). Given the effects of mirtazapine on sleep EEG and hormones that have been reported so far, it appeared to be of great interest to investigate these axes simultaneously.

A bidirectional interaction exists between sleep EEG and sleep-related hormone secretion. Hormones play a key role in normal sleep regulation and in changes of sleep during depression as well. Particularly, the balance between the sleep-promoting GH-releasing hormone (GHRH) and the sleep-impairing key hormone of the HPA system, CRH, is thought to play a crucial role in normal sleep regulation (Ehlers and Kupfer, 1987; Steiger, 2002). CRH overactivity was shown to contribute to the occurrence of the characteristical symptoms of depression, including disturbed sleep and loss of appetite and weight (Holsboer et al, 1988; Nemeroff, 1996; Holsboer, 2000). Besides CRH overactivity, elevated glucocorticoid levels may lead to sleepEEG changes in patients with depression (Antonijevic and Steiger, 2003). Furthermore, enhanced HPA activity is thought to contribute to blunted melatonin levels (Kellner et al, 1997) and to elevated leptin levels (Antonijevic et al, 1998) in depression. To further elucidate the effects of mirtazapine on sleep and endocrine activity and the related mechanisms including HPA system changes, we performed 
a study in patients with depression. Sleep EEG was studied before active medication and, in order to assess early and late effects, on days 2 and 28 of active treatment. During the first and the third of these sleep-EEG recordings, the nocturnal secretion of cortisol, ACTH, GH, prolactin, ghrelin, and leptin was examined. Sleep EEG was analyzed by conventional and qEEG analysis. Furthermore, DEX-CRH tests were performed at baseline and at the end of the trial.

\section{PATIENTS AND METHODS}

\section{Study Population}

A total of 12 subjects were recruited consecutively from inpatients of our hospital. Out of these, 10 completed the study protocol. There were seven women and three men with a mean age of $39.9 \pm$ SD 4.2 (range 24-63) years. The patients met the ICD-10 diagnoses (World Health Organization, 1993) for major depression single or recurrent (F32.1 $(n=4)$, F32.2 $(n=4)$, or F32.3 $(n=1))$. In one patient, a depressive episode related to a bipolar disorder was diagnosed (F31.4). The diagnosis was established by a structured clinical interview (SCID; German version: SKID) (Spitzer et al, 1987), which was performed by a senior psychiatrist. A minimum score of 18 points on the 21-item Hamilton Depression Rating Scale (HDRS) (Hamilton, 1960) was required to enter the study. The duration of the present episode was in the range from 2 to 68 weeks. The study protocol was approved by the Ethics Committee of the Bavarian Physicians Board (Bayerische Landesärztekammer) and the patients provided written informed consent before inclusion in the study. Patients with a history of primary sleep disorder, significant medical disorders, comorbid psychiatric disorders, current alcohol or substance abuse, and suicidal ideation were excluded from the study. The results of physical examination, electrocardiogram (ECG), EEG, blood chemistry, and hematology were within normal limits. Psychotropic drugs were discontinued for at least 1 week in five patients (clozapine, trimipramine and zopiclone, and amitriptyline in one patient each, and St John's Wort in two patients) before the study initiation. None of the subjects worsened during the wash-out period. No subjects had been taking fluoxetine or other CNS-active substances, making a longer wash-out period necessary.

Two female patients (77 years old (ICD F32.2) and 43 years old (ICD F32.2)) dropped out during the trial. They improved distinctly, but did not agree to participate at the re-tests of the DEX-CRH test and sleep endocrinology.

\section{Study Design}

The five patients who had been treated with psychoactive drugs before entering the study went through a 7-day washout phase. Throughout the study, chloralhydrate at a dosage up to $2 \mathrm{~g}$ was permitted as an additional medication for severe sleep disturbances. No other psychotropic drugs were prescribed. Active medication with mirtazapine (Remergil, Organon, Oberschleissheim, Germany) was started at $15 \mathrm{mg}$ on day 1 and then increased to $30 \mathrm{mg}$ at day 2. On day 14 of the study, if there had not yet been a therapeutic effect, the dosage was increased to $45 \mathrm{mg}$. The treatment phase lasted 4 weeks.

\section{Psychometric Assessments}

The patients were rated by an experienced psychiatrist at days $-1,7,14$, and 28 . Psychopathology was evaluated with the 21-item HDRS (Hamilton, 1960) and with the Montgomery-Asberg Depression Rating Scale (MADRS; Montgomery and Asberg, 1979).

\section{Plasma Concentrations}

At the days of psychometric assessment, blood samples were collected at 0800 for analysis of mirtazapine plasma concentrations. To do this, plasma mirtazapine was extracted with a liquid-liquid extraction procedure and then measured after HPLC with UV absorption and fluorescence. For this, $100 \mu \mathrm{l}$ internal standard (protriptyline $2 \mu \mathrm{g} / \mathrm{ml}), 1000 \mu \mathrm{l}$ sodium hydrogencarbonate $(2 \mathrm{M}, \mathrm{pH}$ 10.5 ), and $5 \mathrm{ml} n$-hexane with $1.5 \%$ isoamylalcohol were added to $1000 \mu \mathrm{l}$ plasma. After shaking for $20 \mathrm{~min}$ and centrifugation for $15 \mathrm{~min}$ at 4000 r.p.m., the organic phase was transferred to $250 \mu \mathrm{l}$ of $0.85 \%$ phosphoric acid. The sample was again shaken for $20 \mathrm{~min}$, centrifuged for $15 \mathrm{~min}$ at 4000 r.p.m., and the lower watery phase was analyzed by HPLC. We used a reversed-phase Luna $5 \mu \mathrm{C} 18(2)$ $250 \times 4.6 \mathrm{~mm}$ column (Phenomenex, Torrance, USA), $60^{\circ} \mathrm{C}$, mobile phase flow $1 \mathrm{ml} / \mathrm{min}$. A mobile phase gradient with acetonitrile and phosphoric acid $\left(1.5 \mathrm{ml}\right.$ of $85 \% \mathrm{H}_{3} \mathrm{PO}_{4} / \mathrm{l}$, $\mathrm{pH} 3.5$, adjusted with $\mathrm{NaOH}$ ) was used for the chromatography analysis (mirtazapine $5-33 \%$ acetonitrile for $30 \mathrm{~min}$ ). The substances were determined by UV absorption $(214 \mathrm{~nm})$ and fluorescence at suitable wavelength (mirtazapine $295 / 370 \mathrm{~nm}$, protriptyline $295 / 420 \mathrm{~nm}$ ). The extraction recovery was $>90 \%$, and the intra- and interday variation coefficient was $<10 \%$.

\section{Sleep-EEG Recordings}

Polysomnography (PSG) was performed the night before active medication was started (night -1 ), after 2 days of treatment (night 2) in order to assess the effects of early medication, and finally after 28 days of treatment (night 28) at the end of the trial. The sleep laboratory is located in the same building and has similar equipment as the patients' rooms. Each sleep examination was preceded by an adaptation night. The timing of mirtazapine administration was 2200 hours.

The sleep recordings were scheduled from 2300 to 0700 hours. The PSG at the adaptation night and at the sleep examination included two EEG leads (C3-A2, C4-A1), electro-oculogram (EOG), mental electromyogram (EMG), and ECG. For the EEG recording, the time constant was set to $0.3 \mathrm{~s}$, the low-pass filter to $70 \mathrm{~Hz}$, and the sensitivity to $7 \mu \mathrm{V} / \mathrm{mm}$. The EEG was digitized with a sampling rate of $250 \mathrm{~Hz}$. During adaptation nights, no EEG recordings were performed.

\section{Conventional Sleep-EEG Analysis}

Sleep stages were scored in $30 \mathrm{~s}$ epochs by experienced raters according to the standard criteria (Rechtschaffen and Kales, 1968). The raters were unaware of the examination conditions. The following sleep parameters were calculated: 
sleep latency, as time from 'lights off' to the first epoch of stage 2 non-REM sleep (NREMS), REM latency, as time from the first epoch of stage 2 NREMS to the first epoch of REM sleep including intervening awakenings, REM density, as the percentage of $3 \mathrm{~s}$ mini-epochs of REM sleep containing rapid eye movements at all $3 \mathrm{~s}$ mini-epochs of REM sleep, sleep period time, as time from the first epoch of stage 2 NREM to final awakening, total sleep time (including stage 1 NREM), total amount, and relative amount as percentage of sleep period time for stages wake, 1, 2, REM and SWS. SWS represents combined stages 3 and 4, which were not analyzed separately, because only five subjects achieved stage 4 during all three examination nights.

\section{Quantitative Sleep-EEG Analysis}

After scoring of sleep stages, a single EEG derivation was subjected to qEEG using a fast Fourier transform routine (FFT). The C3-A2 or C4-A1 derivation was selected individually for each subject with regard to EEG quality. In each subject, the EEG recordings obtained from the same EEG lead were compared between all examination nights. The artifacts and arousals, defined according to American Sleep Disorders Association (ASDA) criteria (American Sleep Disorders Association, 1992), were rejected prior to qEEG by visual inspection. The FFT was performed using rectangular overlapping windows of $2.56 \mathrm{~s}$ length (frequency resolution $0.39 \mathrm{~Hz}$ ). The spectral values from 12 adjacent windows correspond to the $30 \mathrm{~s}$ epoch of visual sleep stages scoring. The EEG power spectra were calculated as mean values for the NREM sleep (stages 2-4 NREM) and separately for each sleep stage. The 48 frequency bins from frequency range between 0.78 and $19.1 \mathrm{~Hz}$ were accumulated to low-delta $(0.8-1.9 \mathrm{~Hz})$, delta $(0.8-3.9 \mathrm{~Hz})$, theta (4.3-7.8 Hz), alpha $(8.2-11.7 \mathrm{~Hz})$, sigma $(12.1-14.8 \mathrm{~Hz})$, and beta $(15.2-19.1 \mathrm{~Hz})$ frequency bands.

Since there was a substantial difference in the total NREMS time between three examination nights (Table 3), the analysis of spectral composition of NREMS was restricted for the longest common amount of NREMS, accumulated from sleep onset onwards. It turned out to be $155.5 \mathrm{~min}$. Such an approach offers the possibility to compare the spectral EEG composition in the same amount of NREMS in all nights for all subjects. The rationale for such analysis is that the mean power over total NREMS may change according to the time spent in NREMS. Delta power is usually high in the first third of night sleep and it is low at the end of sleep, when the faster EEG rhythms dominate the sleep-EEG spectrum. For this reason, a longer sleep time may result in a lower mean delta power and an increased mean power of faster frequencies. For a detailed discussion of this methodological problem, see Van Bemmel et al (1995). Relative power values are presented in Figures 1 and 2 according to a suggestion by Dijk et al (1989).

\section{Investigation of Nocturnal Hormone Secretion}

At days -1 and 28 at 1945 hours, an indwelling vein catheter was inserted into a forearm vein in order to investigate nocturnal hormone secretion with a 'throughthe-wall device' that is, the blood samples were collected via a long catheter from a room adjacent to the sleep

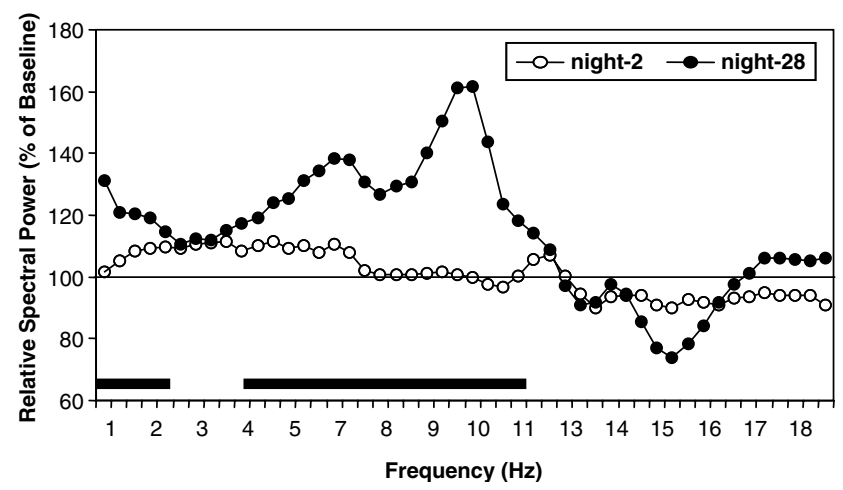

Figure I Spectral EEG composition of the largest common amount of NREM sleep (=155.5 min) 2 days (night 2) and 4 weeks (night 28) after beginning mirtazapine administration. The values for all frequency bins are plotted as a percentage of baseline night $(=100 \%)$. The frequency ranges in which the values varied significantly (ANOVA, $p<0.05$ ) over all three examination nights are indicated by black bars above the abscissa.

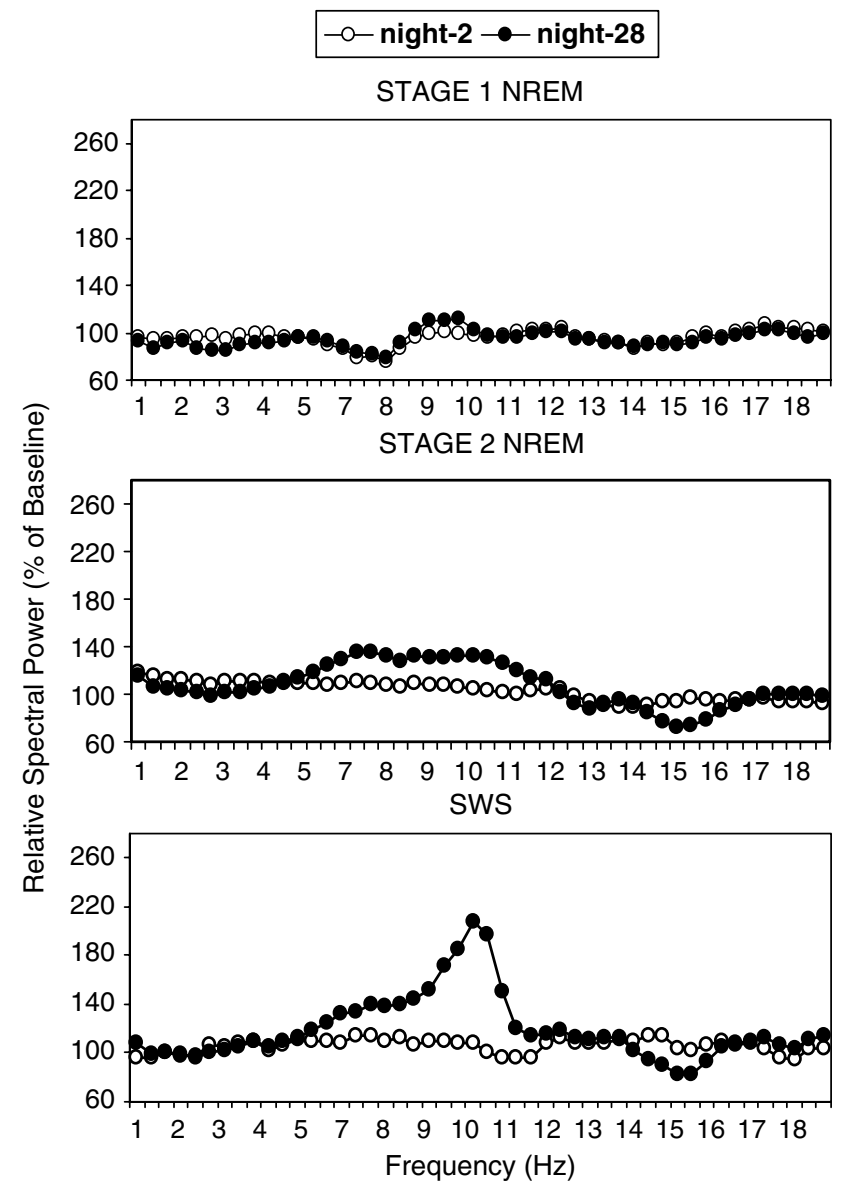

Figure 2 Spectral EEG composition in each of NREM sleep stages 2 days (night 2) and 4 weeks (night 28) after beginning mirtazapine administration. The values for all frequency bins are plotted as a percentage of baseline night (=100\%). The increase of alpha activity was apparent only at week 4 and was, in particular, related to SWS.

laboratory. The specimens were taken every $30 \mathrm{~min}$ from 2000 to 2200 hours and every $20 \mathrm{~min}$ from 2200 to 0700 hours. About $5 \%$ of the nocturnal blood samples were missing for different reasons (temporary vein spasms, low 
plasma yield): missing data were estimated by individual linear interpolation of the antecedent and subsequent values.

\section{DEX-CRH Test}

At days -4 and 25, $1.5 \mathrm{mg}$ DEX (Fortecortin, Merck, Darmstadt, Germany) was given orally at 2300 hours. At days -3 and 26, the DEX-CRH test was performed as described elsewhere (Heuser et al, 1994). Regarding the combined DEX-CRH tests, the cortisol concentrations before the injection of CRH (baseline) and the total (total AUC) and the net area under the plasma cortisol concentration curve (net AUC) were analyzed. The net AUC is the total AUC minus the baseline ACTH or cortisol level.

\section{Endocrine Analysis}

Plasma ACTH (Ria Kit J ${ }^{125}$; Nichols Institute, San Juan Capistrano, CA, USA; intra- and interassay coefficients of variation $<8 \%$ ), cortisol (Ria Kit ${ }^{125}$; ICN Biomedicals, Carson, CA, USA; intra- and interassay coefficients of variation $<7 \%$ ), ghrelin (Phoenix, Belmont, CA, USA; intra- and interassay coefficients of variation $<13 \%$ ), and leptin (Ria Kit J ${ }^{125}$; Linco Research, St Charles, MO, USA; intra- and interassay coefficients of variation $<8 \%$ ) concentrations were measured by radioimmunoassay, and GH (Advantage; Nichols Institute, San Juan Capistrano, CA, USA; intra- and interassay coefficients of variation $<10 \%$ ), prolactin (Advantage; Byk-Santec, Dietzenbach, Germany; intra- and interassay coefficients of variation $<7 \%$ ), and melatonin (DRG, Marburg, Germany; intra- and interassay coefficients of variation $<8 \%$ and $15 \%$ ) concentrations were determined by chemiluminescence. Random samples for each hormone were analyzed in duplicate. According to standard procedures for time series, the remaining specimens were analyzed only once. Areas under the plasma concentration curves (AUC) were calculated for the first (2200 to 0300 hours, for example, $1 \mathrm{~h}$ prior to sleep-EEG recording and the first half of sleep-EEG recording time) and for the second part of the night (0300 to 0700 hours, second half of the sleep-EEG recording time) and for the total night (2200 to 0700 hours) by applying the trapezoid rule (Yeh and Kwan, 1978). Maximum concentrations were identified as well. Owing to technical reasons, collection of blood was incomplete in three patients. They were omitted from the analysis.

\section{Statistical Analysis}

Change before and after mirtazapine treatment was analyzed nonparametrically with Wilcoxon matched pairs tests for repeated measures. PSG was evaluated three times (nights -1, 2, and 28). Changes were evaluated with nonparametric Friedman tests and pairwise Wilcoxon matched pairs tests in case of a significant Friedman test. Pairwise post hoc comparisons were corrected according to the Bonferroni-Holm procedure (Holm, 1979) in order to maintain the variable-wise alpha error. For the assessment of associations, nonparametric Spearman's rho correlation coefficients were calculated. The level of significance was set to $p=0.05$. Mean values and standard deviations are reported.

\section{RESULTS}

Psychometry, Plasma Concentrations, and Weight Gain

Depressive symptoms assessed by the HDRS total score improved significantly between days -1 and $28(p=0.007)$ from $32.1(\mathrm{SD}=7.3)$ to $15.5(\mathrm{SD}=6.7)$. An HDRS subscore derived from the three sleep items (nos. 4, 5, and 6) of this rating scale improved significantly from $5.2(\mathrm{SD}=1.1)$ to $1.7(\mathrm{SD}=1.4)(p=0.042)$. Five patients can be regarded as treatment responders (HDRS after 4 weeks of treatment $\leq 50 \%$ of the HRDS before initiation of the treatment) and two of them as remitters (HDRS $<10$ ). A similar picture emerged with the MADRS (baseline score $=34.4, \mathrm{SD}=7.8$; scores after 4 weeks $=19.1, \mathrm{SD}=7.5 ; p=0.008)$. The body weight increased significantly $(p=0.005)$ from $66.2 \mathrm{~kg}$ $(\mathrm{SD}=12.6)$ to $69.4 \mathrm{~kg}(\mathrm{SD}=13.5)$. The mean dosage of mirtazapine was $30.0 \mathrm{~g}(\mathrm{SD}=7.1)$ at day 7 and $49.5 \mathrm{~g}$ $(\mathrm{SD}=15.9)$ at day 28. Mirtazapine plasma levels were $27.6 \mathrm{ng} / \mathrm{ml}(\mathrm{SD}=21.8)$ at day 7 and $55.5 \mathrm{ng} / \mathrm{ml}(\mathrm{SD}=21.6)$ at day 28. An additional hypnotic medication with chloralhydrate up to $500 \mathrm{~g}$ was necessary in five of the patients in some of the nights of the 2 first weeks of treatment.

\section{Conventional Sleep EEG}

The analysis of conventional sleep parameters revealed a substantial improvement in sleep continuity and sleep architecture, which was present already at the second day of treatment and persisted after 28 days of treatment (Table 1).

This includes increased total sleep time and NREM sleep time (trend after 2 days, significant after 28 days of treatment), improved sleep efficiency, reduced time spent awake (trend after 2 days, significant for the relative amount after 28 days), and increased stage 2 sleep time (trend after 2 days, significant after 28 days of treatment). The absolute and relative amount of SWS increased after 28 days of treatment. No significant changes were observed for REM sleep parameters.

\section{Quantitative Sleep EEG}

The qEEG of NREM sleep revealed an increase in low-delta, delta, theta, and alpha activity after 28 days of treatment (Table 2). Post hoc tests did not show any significant qEEG changes after 2 days of treatment.

Since the standard EEG frequencies bands are usually insufficient to describe adequately the changes in the EEG spectrum, a statistical analysis at the level of single frequency bins was performed. It revealed a significant increase of power in the low-delta band below $2.3 \mathrm{~Hz}$ at night 28 compared to nights -1 and 2 . The increase in the delta, theta, and alpha bands at night 28 was restricted to frequencies between 3.9 and $10.9 \mathrm{~Hz}$ (Figure 1).

Separate spectral EEG analysis for each sleep stage revealed that the increase of theta and alpha activities at night 28 was significant in stage 2 as well as in SWS, but not in stage 1 . The increase in theta activity in stage 2 NREM 
Table I Sleep-EEG Parameters Before (Night - I), 2 Days After (Night 2), and 28 Days After (Night 28) Initiation of Mirtazapine Treatment $(n=10)$

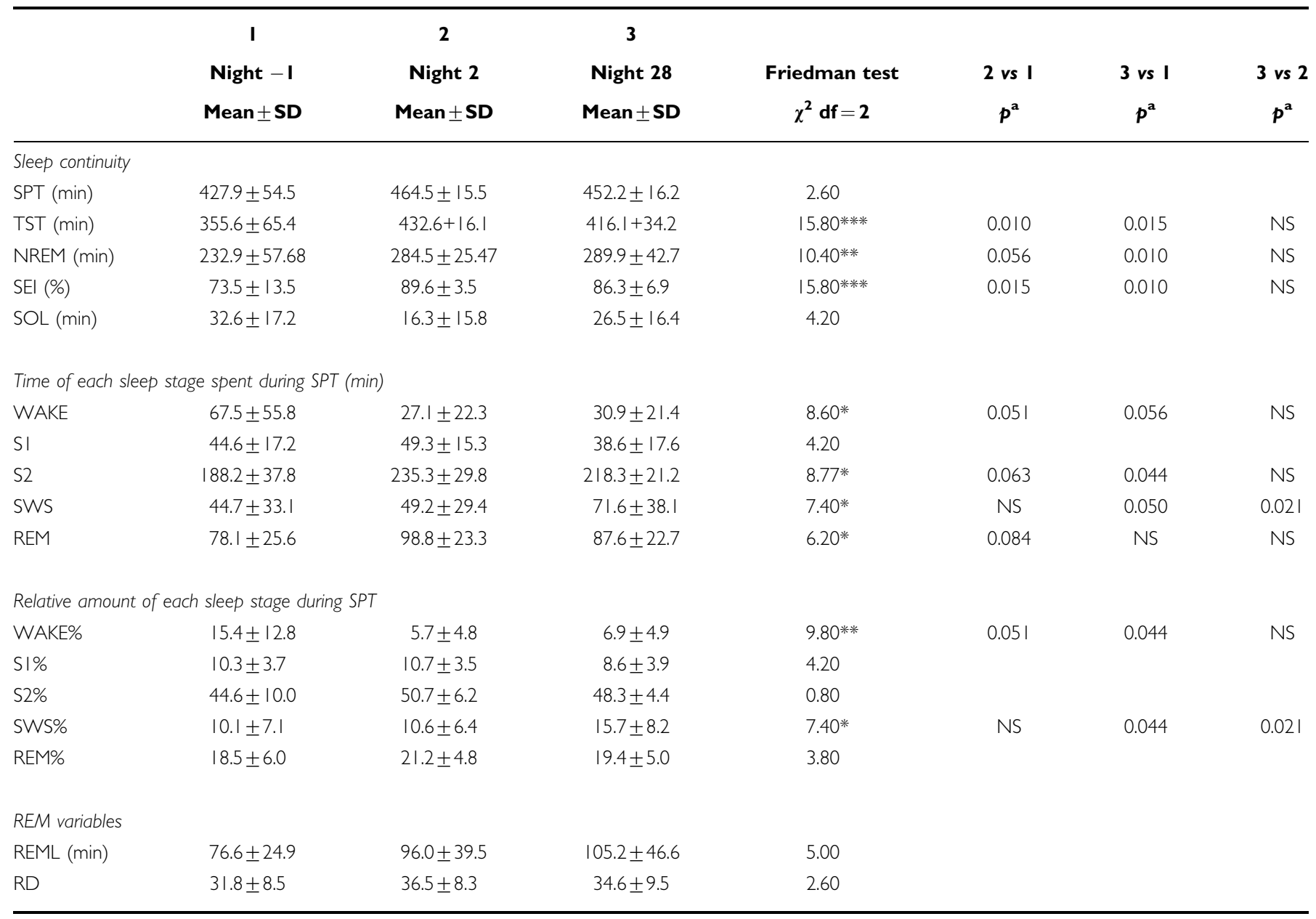

apairwise post hoc Wilcoxon tests, corrected for three simultaneous comparisons according to Bonferroni-Holm.

TIB: time in bed; SPT: sleep period time; TST: total sleep time; NREM: total NREM sleep time (stages 2-4); SEl: sleep efficiency index; SOL: sleep onset latency; REM: REM sleep, SI, S2, SWS; REML: REM latency; RD: REM density, ***p<0.00I, *** $<0.0$ I, *p $<0.05$.

Table 2 Spectral Power $\left(\mu \mathrm{V}^{2}\right)$ in Conventional Frequency Bands Before (Night - I), 2 Days After (Night 2), and 4 Weeks After (Night 28) Initiation of Mirtazapine Treatment in the Largest Common Amount of NREM Sleep (I $55.5 \mathrm{~min})(n=10)$

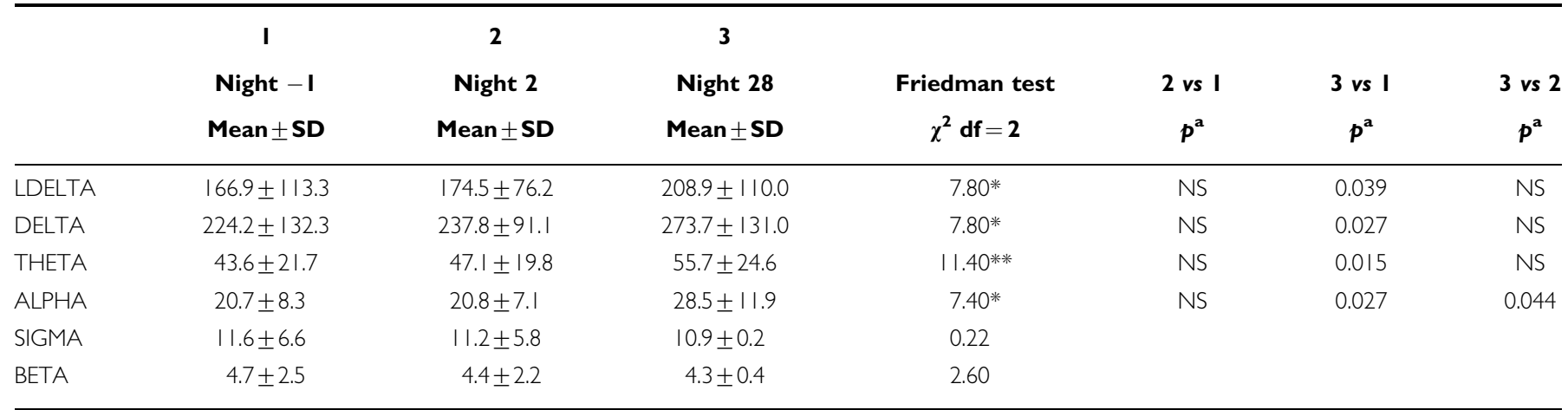

**** $p<0.001$, *** $<<0.01$, *p $<0.05$, NS: nonsignificant.

apairwise post hoc Wilcoxon tests, corrected for three simultaneous comparisons according to Bonferroni-Holm.

was evident in trend already at night 2 . Regarding alpha activity, we observed an increase between nights 28 and -1 during SWS and in trend during stage 2 sleep (Figure 2).
Again, no early effects could be observed after 2 days of treatment. No significant differences were found in the spectral EEG composition of REM sleep. 


\section{Nocturnal Hormone Secretion}

Between nights -1 and 28, cortisol levels decreased during the total night and the second part of the night. Ghrelin and leptin showed changes in opposite direction, as ghrelin levels decreased during the total night and during both parts of the night, whereas leptin levels increased during the same intervals. Melatonin concentrations were elevated during the second part of the night. $\mathrm{ACTH}, \mathrm{GH}$, and prolactin concentrations did not differ between baseline and the end of active mirtazapine treatment (Table 3 and Figure 3). As visual inspection of the course of GH concentrations points to a decrease of GH during night 28 , which may be related to the alpha intrusion in GEEG, we examined the GH concentrations during the individual time frame of the qEEG analysis ( $160 \mathrm{~min}$ in total). Although we did not observe significant differences between the total GH secretion during this time frame between nights -1 and 28 (AUC: $p=0.401$; peak: $p=0.646$ ), we observed lower GH values of the first two samples, that is, at the time when the qEEG analysis was started $(p=0.028)$ and $20 \mathrm{~min}$ later $(p=0.028$; see Figure 4$)$. This difference can partly be explained by the fact that the qEEG analysis during the baseline night started on average at 23:52 $(\mathrm{SD}=32 \mathrm{~min})$, but almost $20 \mathrm{~min}$ earlier $(23: 35, \mathrm{SD}=16 \mathrm{~min})$ at the end of the treatment period $(p=0.041)$. As a result, $\mathrm{qEEG}$ analysis began at night -1 during the $\mathrm{GH}$ peak, but before the onset of GH secretion at night 28 . The peak of the cortisol concentration of the first part of the night occurred $117 \pm 98$ min earlier $(p=0.042)$ after 4 weeks of mirtazapine treatment $(p=0.046)$.

\section{DEX-CRH Test}

We observed a distinct reduction of the ACTH and cortisol response to the combined DEX-CRH test after 4 weeks of mirtazapine treatment. ACTH and cortisol levels at baseline before $\mathrm{CRH}$ injection were not statistically different (Table 4).

\section{DISCUSSION}

We investigated the effects of 4 weeks of mirtazapine treatment on sleep and endocrine activity in patients with depression. The following were our major findings: After mirtazapine, sleep continuity improved rapidly. This effect was sustained after 4 weeks, when SWS also increased. At this time, qEEG analysis showed increases of low-delta activity below $<1 \mathrm{~Hz}$ and of theta and alpha activity. The sleep-related secretion of cortisol and ghrelin was decreased throughout the night, whereas increases of leptin and melatonin occurred during the whole night and the second part of the night, respectively. The DEX-CRH test showed a decrease of HPA activity at day 26 in comparison to baseline, and weight increased on average by approximately $3 \mathrm{~kg}$. These effects show that mirtazapine, besides improving psychopathology, counteracts the key biological symptoms of depression: insomnia, loss of appetite and weight, hypercortisolism, and low melatonin syndrome. This profile of neurobiological effects appears to be specific and as known so far is not shared exactly by any other antidepressant. Mirtazapine's unique pattern of neurotransmitter
Table 3 Hormone Plasma Concentrations Before and After 4 Weeks of Mirtazapine Treatment $(n=7)$

\begin{tabular}{|c|c|c|c|c|c|}
\hline & \multicolumn{2}{|c|}{ Before treatment } & \multicolumn{2}{|c|}{ After treatment } & \multirow[b]{2}{*}{$p$} \\
\hline & $\mathbf{M}$ & SD & $\mathbf{M}$ & SD & \\
\hline \multicolumn{6}{|l|}{ Cortisol } \\
\hline \multicolumn{6}{|l|}{ AUC } \\
\hline Total night & 28798 & 7916 & 20084 & 7078 & 0.018 \\
\hline First part of the night & 8556 & 3639 & 5586 & 2011 & 0.063 \\
\hline Second part of the night & 20242 & 5510 & 14498 & 5766 & 0.028 \\
\hline Maximum (ng/ml) & 135 & 34 & 121 & 41 & 0.028 \\
\hline \multicolumn{6}{|l|}{ ACTH } \\
\hline \multicolumn{6}{|l|}{ AUC } \\
\hline Total night & 9357 & 3314 & 7204 & 1629 & 0.128 \\
\hline First part of the night & 3309 & 1204 & 2697 & 691 & 0.237 \\
\hline Second part of the night & 6048 & 2528 & 4507 & 1078 & 0.128 \\
\hline Maximum (pg/ml) & 54.6 & 32.0 & 35.0 & & 40.128 \\
\hline \multicolumn{6}{|l|}{$\mathrm{GH}$} \\
\hline \multicolumn{6}{|l|}{$A \cup C$} \\
\hline Total night & 1126 & 546 & 924 & 368 & 0.091 \\
\hline First part of the night & 863 & 593 & 728 & 384 & 0.237 \\
\hline Second part of the night & 263 & 181 & 196 & 105 & 0.310 \\
\hline Maximum (ng/ml) & 8.2 & 5.2 & 7.1 & & 90.237 \\
\hline \multicolumn{6}{|l|}{ Prolactin } \\
\hline \multicolumn{6}{|l|}{ AUC } \\
\hline Total night & 9686 & 4390 & 10457 & 8458 & 0.735 \\
\hline First part of the night & 4487 & 1652 & 5366 & 5310 & 0.735 \\
\hline Second part of the night & 5198 & 2875 & 5091 & 3176 & 0.866 \\
\hline Maximum (ng/ml) & 36.4 & 22.0 & 32.7 & & 40.866 \\
\hline \multicolumn{6}{|l|}{ Melatonin } \\
\hline \multicolumn{6}{|l|}{ AUC } \\
\hline Total night & 26419 & 25647 & 29453 & 21956 & 0.176 \\
\hline First part of the night & 11350 & 9549 & 11948 & 6554 & 0.499 \\
\hline Second part of the night & 15070 & 6354 & 17505 & 16658 & 0.018 \\
\hline Maximum (ng/ml) & 102 & 96 & $13 \mid$ & 93 & 0.063 \\
\hline
\end{tabular}



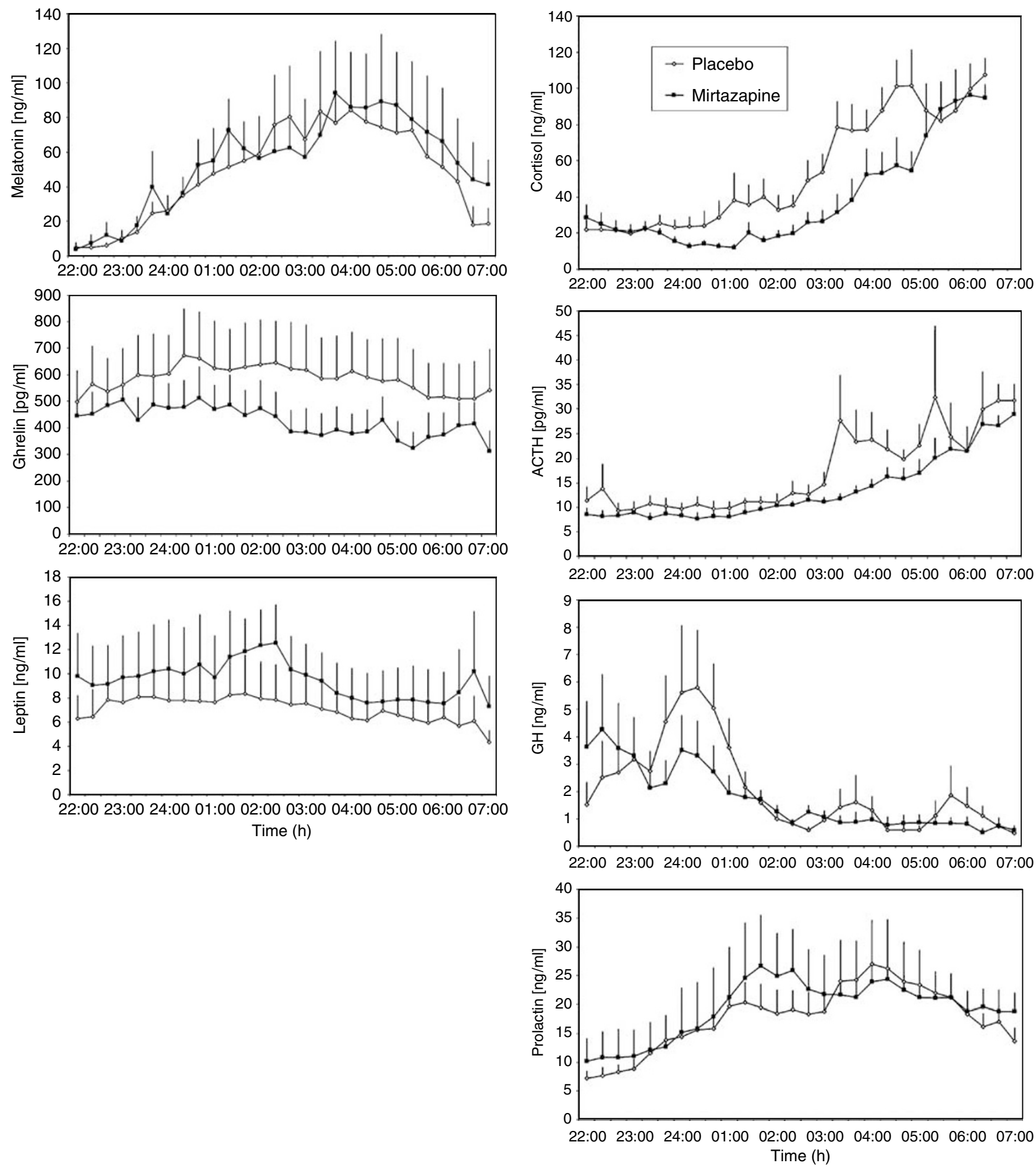

Figure 3 Nocturnal hormone secretion before and after 4 weeks of treatment with mirtazapine.

modulation helps to explain the mechanisms of action of these effects. The substance was classified as a NaSSA, as it is an antagonist at presynaptic alpha ${ }_{2}$ receptors and at postsynaptic 5 -hydroxytryptamine $(5 \mathrm{HT})_{2}$ and $5-\mathrm{HT}_{3}$ receptors. Furthermore, it acts at the histamine $\mathrm{H}_{1}$ receptor, which mainly accounts for the sedating effect of the substance (De Boer, 1995).

The rapid improvement in sleep continuity as increases of total sleep time and sleep efficiency and in sleep architecture (decrease of wake time) was found similarly in previous studies in normal controls (Ruigt et al, 1990) and depressed patients (Winokur et al, 2000). Moreover, in healthy controls, acute mirtazapine administration $(30 \mathrm{mg})$ increased SWS (Ruigt et al, 1990; Aslan et al, 2002). Similarly, Schittecatte et al (2002a) reported an increase of SWS after a 2-day treatment of depressed patients with mirtazapine. In accordance with Winokur et al (2000), we did not observe a change of SWS shortly after the beginning of mirtazapine treatment. This variance may be explained by differences in sample composition. Winokur et al $(2000,2003)$ investi- 


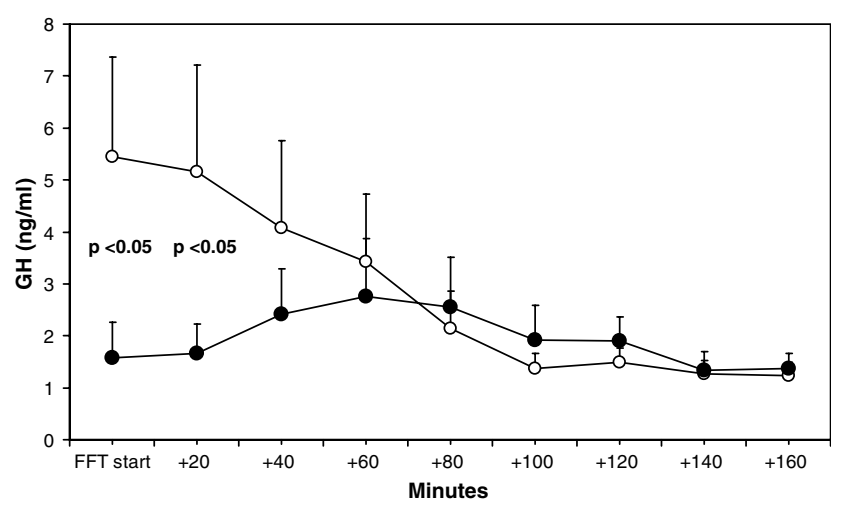

Figure $4 \mathrm{GH}$ secretion during the individual time frame of the $q E E G$ analysis at night - I (empty circles) and night 28 (filled circles).

Table 4 ACTH and Cortisol Response to the Combined DEX-CRH Test Before and After 4-Weeks of Mirtazapine Treatment $(n=7)$

\begin{tabular}{|c|c|c|c|c|c|}
\hline & \multicolumn{2}{|c|}{ Before treatment } & \multicolumn{2}{|c|}{ After treatment } & \multirow[b]{2}{*}{$p$} \\
\hline & $\mathbf{M}$ & SD & $\mathbf{M}$ & SD & \\
\hline \multicolumn{6}{|c|}{ ACTH (pg/m/ min) } \\
\hline Baseline & 9.99 & 8.85 & 6.04 & 1.96 & 0.091 \\
\hline Total AUC & 1581.88 & 875.63 & 765.63 & 258.76 & 0.028 \\
\hline Net AUC & 846.88 & $3|5.4|$ & 335.63 & 179.99 & 0.028 \\
\hline \multicolumn{6}{|c|}{ Cortisol (ng/m/min) } \\
\hline Baseline & 32.98 & 46.67 & 12.06 & 4.61 & 0.463 \\
\hline Total AUC & 4599.48 & 4256.21 & |59|.80 & I I 23.74 & 0.063 \\
\hline Net AUC & 2125.84 & 1632.93 & 687.15 & 1019.20 & 0.028 \\
\hline
\end{tabular}

gated depressed patients with insomnia. Also in our study, nine of 10 patients reported suffering from disturbed sleep before treatment. Information about this issue is not provided by Schittecatte et al (2002a). We found, however, an increase of SWS at day 28. Despite the sleep-promoting effect of mirtazapine, in some of the patients additional administration of chloralhydrate was required during some nights of the 2 first weeks of active treatment. This observation suggests that, in some patients during the early treatment phase with mirtazapine, the prescription of a hypnotic may be useful.

Furthermore, one should keep in mind that in our hands during nights -1 and 28 , but not during night 2 , blood was collected by a long catheter. There are conflicting results concerning nocturnal blood sampling that may have no major effect on sleep EEG in a previous study (Kerkhofs et al, 1989) or may disturb sleep in elderly subjects (Vitiello et al, 1996). This methodological issue may contribute to differences between nights -1 and 2. Two studies reported an increase of REM latency: one in healthy subjects (Ruigt et al, 1990) and the other in depressed patients (Schittecatte et al, 2002a). This finding could not be replicated in all other reports (Winokur et al, 2000, 2003; Aslan et al, 2002), including the present study. REM density, which was not calculated in the previous studies (Ruigt et al, 1990;
Winokur et al, 2000, 2003; Aslan et al, 2002; Schittecatte et al, 2002a), was not changed after mirtazapine. The effects of mirtazapine on conventional sleep-EEG variables differ from most other antidepressants, as these substances suppress distinctly REM sleep (Staner et al, 1999; Armitage, 2000). Similar to mirtazapine, trimipramine (Sonntag et al, 1996) and the CRH-1 receptor antagonist R121919 (Held et al, 2004) increased SWS and decreased wakefulness in patients with depression and did not diminish the time spent in REM sleep. REM density decreased after the latter substance, but not after trimipramine.

qEEG analysis revealed changes in spectral composition of NREMS, in particular at week 4 of mirtazapine treatment. After 2 days of mirtazapine treatment, the only alteration in EEG spectrum was found in stage 2 as an increase of theta power. Whereas the absence of increase in slow-wave activity shortly after the start of mirtazapine treatment corresponds to the late increase of SWS, the increase in alpha activity at week 4 but not at week 1 is surprising. Obviously, this effect did not result from an acute action of mirtazapine but rather from the increase of mirtazapine dose after 2 weeks of therapy or from adaptational changes after prolonged mirtazapine treatment.

Drugs with 5-HT2-blocking properties improve sleep by shortening sleep latency and increasing total sleep time, sleep efficiency index, and SWS (Thase, 1999). In qEEG, the selective 5-HT2 antagonists seganserin and ritanserin prompted a bimodal increase of spectral power in the lower delta $(0.5-1 \mathrm{~Hz})$ and theta $(5-8 \mathrm{~Hz})$ frequencies range with a trough at about $4 \mathrm{~Hz}$ (Idzikowski et al, 1986; Dijk et al, 1989; Brandenberger et al, 1996). The changes of sleep architecture and qEEG in the delta and theta range in the present study are in accordance with these reports. Similar effects were observed after selective stimulation of 5-HT1 receptors with ipsapirone (Seifritz et al, 1996). The enhancement of serotoninergic neurotransmission resulting from 5-HT2 blockade by mirtazapine is specifically mediated via 5HT1 receptors (Fawcett and Barkin, 1998). This explains the similarities between ipsapirone and mirtazapine in their influence on the sleep-EEG spectrum.

Substances with nonselective action on the serotoninergic system, for example, 5-HT reuptake inhibitors (SSRIs), often induce disturbed sleep as an increase in intermittent wakefulness, whereas SWS is largely unaffected by these substances (Saletu et al, 1991; Rush et al, 1998). No alterations of the spectral composition of sleep EEG were found during subchronic treatment with paroxetine in healthy subjects (Röschke et al, 1997). Another study in depressed male therapy responders showed a decline of power in the higher frequency sigma range during treatment with paroxetine as well as tianeptine, which enhances serotonin reuptake (Murck et al, 2003). Treatment with citalopram resulted in suppression of spectral power in the $8-9 \mathrm{~Hz}$ range. In these studies, no influence of SSRIs on delta power was observed (Röschke et al, 1997; Murck et al, 2003). 5-HT antagonists at presynaptic serotonergic 5-HT1A autoreceptors enhance serotonin release by suppression of the inhibitory effect of 5-HT1A autoreceptors on raphe nuclei neurons (Sharp et al, 1989). Pindolol, a 5HT1A antagonist, suppresses REM sleep, increases intermittent wakefulness, and has no influence on SWS. In the EEG power spectrum, pindolol reduces power in the delta, 
theta and, like citalopram, low-alpha frequency range (Seifritz et al, 1997). On the contrary, vilazodone (EMD 68843), acting as an SSRI and also as a postsynaptic 5-HT1 agonist, increases delta activity and reduces sigma activity. In sleep architecture, vilazodone suppresses REM sleep and increases intermittent wakefulness, but it also increases SWS (Murck et al, 2001). However, none of these studies reported an increase in the alpha frequency range. Therefore, an additional mechanism to postsynaptic 5-HT2 blockade and 5-HT1 stimulation has to be considered to explain the increase in alpha power during mirtazapine treatment.

Clonidine, an agonist at presynaptic adrenergic alpha 2 receptors, has a potent influence on alpha activity. In healthy volunteers, clonidine suppresses alpha activity in wake EEG (Yamadera et al, 1985; Bischoff et al, 1998). In accordance with these studies, the blockade of alpha 2 receptors with mirtazapine results in the increase of alpha power. However, some studies in animal models showed that clonidine can also suppress alpha activity (Pickworth et al, 1982; Emilien, 1990) and promote sleep (Ramesh and Kumar, 1998). Moreover, a recent study investigating the effects of mirtazapine on the clonidine REM suppression test (CREST) showed that blunted REM sleep response to clonidine in depressed patients normalizes during mirtazapine treatment. This effect was discussed as a possible upregulation and increase in sensitivity of adrenergic alpha 2 receptors during the treatment with mirtazapine, secondary to the antagonistic properties of mirtazapine at these receptors. It was proposed that subsensitivity of alpha 2 adrenergic receptors is a trait marker of major depression (Schittecatte et al, 2002b). Therefore, the adaptational changes in the noradrenergic system or dose-related effects can cause changes in alpha activity after 4 weeks of mirtazapine treatment and explain the absence of changes in the NREM sleep-EEG spectrum after acute mirtazapine administration. The involvement of adaptational mechanisms is further supported by a study with Org4428, a highly specific norepinephrine reuptake inhibitor. An acute administration of Org4428 does not result in EEG spectrum changes in the frequency range $1-15 \mathrm{~Hz}$, despite strong effects on sleep architecture including REM sleep suppression and increase of stage 2 (Van Bemmel et al, 1999). Also of interest is an earlier study with trazodone, acting as SSRI 5-HT2 antagonist, alpha 1 and weak alpha 2 antagonist, with an influence on the histaminergic system. Trazodone suppresses EEG activity in the $13-14 \mathrm{~Hz}$ range. Moreover, after trazodone withdrawal, a decrease of power in $1 \mathrm{~Hz}$ became apparent. Trazodone has no influence on theta and alpha activity (Van Bemmel et al, 1995).

Whereas increase of delta and theta power in the sleepEEG spectrum is a sign of higher sleep intensity and deeper sleep, the increase of alpha activity may be presumed to be a sign of increased arousal and nonrestorative sleep. The frequent intrusion of alpha activity in the sleep of psychiatric patients was described in detail by Hauri and Hawkins (1973). As alpha intrusion was, like in the present study, especially related to SWS, such a sleep-EEG pattern was termed as alpha-delta sleep or alpha anomaly and was connected to increased autonomic activation and arousal in sleep. However, alpha activity in alpha-delta sleep has characteristics other than occipital waking or arousal- related alpha activity, being generally 1-2 cycles slower and showing a fronto-central topographic distribution (Hauri and Hawkins, 1973). Furthermore, it also occurs in healthy subjects, free from clinical disorders or complaints of sleep disturbances. Hence, the alpha anomaly alone does not result in nonrestorative sleep and the former hypothesis about a link between alpha anomaly and disturbed sleep cannot be further maintained (Pivik and Harman, 1995). In contrast, even an opposite interpretation of alpha anomaly has been proposed. It should be associated with a sleepmaintaining, but not disruptive, process (Pivik and Harman, 1995). Further studies detailing the physiological significance of continuous, background alpha activity in NREM sleep are needed to clarify these issues.

Besides modulation of neurotransmitters, the endocrine effects of mirtazapine, particularly on the HPA system and on melatonin, may be related to its sleep-promoting action. It is thought that a reciprocal interaction of CRH and GHRH plays a key role in sleep regulation (Ehlers and Kupfer, 1987; Steiger, 2002). During depression, a change of the GHRH/CRH ratio in favor of CRH is hypothesized to lead to shallow sleep and REM sleep desinhibition. This is supported by the finding that CRH impairs sleep in normal controls (Holsboer et al, 1988; Vgontzas et al, 2001). Furthermore, elevated glucocorticoid levels appear to contribute to the sleep-EEG changes in depression (Antonijevic and Steiger, 2003). As mentioned before, CRH-1 receptor antagonism improved sleep architecture in depressed patients (Held et al, 2004) whereas qEEG remained unchanged. The latter result may be due to the small size of the investigated subgroup of the sample. Another difference between mirtazapine and the $\mathrm{CRH}-1$ receptor antagonist R121919 is the lack of a decrease in REM density after mirtazapine. The increase of melatonin during the morning hours in our study fits with a similar observation in normal controls (Palazidou et al, 1989). This effect may be explained by the alpha-adrenergic action of the substance. Furthermore, it is of interest that nocturnal melatonin levels were blunted after repetitive $\mathrm{CRH}$ administration in normal controls (Kellner et al, 1997). Therefore, suppression of HPA activity may have contributed to the increase of melatonin after mirtazapine.

The effects of mirtazapine on the sleep-related secretion of cortisol, GH, and prolactin resemble those reported after acute administration of the drug to normal control subjects at daytime (Laakmann et al, 1999; Schüle et al, 2002b). In accordance with these studies, we found a blunting of nocturnal cortisol levels throughout the night, whereas GH and prolactin secretion remained unchanged. When we analyzed $\mathrm{GH}$ levels during the interval with qEEG analyis, however, decreased concentrations were found for the two specimens collected after the start of the analyis. This may be explained by the fact that during night -1 the analysis started during the GH surge, whereas it started during night 29 before the onset of GH secretion. On the other hand, given the strong ties between SWS and GH (Van Cauter et al, 2004; Steiger, 2003 Frontiers), the arousals related to alpha intrusion may contribute to this change. Similar to the decrease of nocturnal cortisol levels in the present study, salivary cortisol was blunted in depressed patients after 1 day of treatment (Laakmann et al, 2004). As discussed by Schüle et al (2002b), the antagonistic action of mirtazapine 
on alpha $2,5 \mathrm{HT}_{2}$, and $\mathrm{H}_{1}$ receptors appears to contribute to the blunting of cortisol. In our study, ACTH secretion showed only a nonsignificant trend to decrease. This is in contrast to the finding that ACTH was blunted after mirtazapine in normal controls (Laakmann et al, 1999; Schüle et al, 2002b). Elevated nocturnal cortisol (Linkowski et al, 1987; Steiger et al, 1989) and ACTH (Linkowski et al, 1987) levels are robust findings in acutely depressed patients and mirror HPA overactivity in affective disorders. Cortisol levels decreased after recovery in drug-free patients (Steiger et al, 1989) and after a 4-week treatment of depressed patients with trimipramine but not with imipramine (Sonntag et al, 1996). In the latter study, the effects of trimipramine and imipramine on psychometry were equal. Obviously a 4-week drug treatment of depression does not result generally in a blunting of cortisol. This appears to be a specific effect of mirtazapine and trimipramine separately. In contrast to the blunting of mirtazapine, acute administration of various antidepressants with noradrenaline and 5-HT uptake-inhibiting properties to normal controls stimulated cortisol (reviewed by Laakmann et al, 1999). Similarly, after 1 week administration of amitriptyline, clomipramine, and moclobemide, nocturnal cortisol levels increased in normal controls whereas they were blunted after trimipramine (Steiger et al, 1993). Trimipramine differs in its endocrine effects from mirtazapine, as it enhanced sleep-related prolactin secretion after 4 weeks of treatment in depressed patients (Sonntag et al, 1996).

Whereas we did not observe a clear effect of mirtazapine on nocturnal ACTH levels, the results of the DEX-CRH test showed a significant decrease of cortisol and ACTH values after $\mathrm{CRH}$ at day 28, whereas baseline values remained unchanged. This finding is similar to the report by Schüle et al (2003), who compared the DEX-CRH test between baseline and 1 week treatment. From their and our findings, we conclude that mirtazapine exerts an early suppressing effect on HPA activity, which appears to persist after 4 weeks of treatment.

After 4 weeks of treatment with mirtazapine, we found opposite changes of nocturnal ghrelin and leptin levels. Ghrelin concentrations decreased whereas leptin concentrations increased. During the same interval, a slight increase in body weight occurred. Most patients had reported a loss of appetite and weight before treatment. The changes in ghrelin and leptin resemble the effects of weight gain in some, but not all other conditions. In patients with anorexia, ghrelin decreased when their weight increased (Otto et al, 2001). Normal male controls were overfed for 84 days. Their body weight increased more distinctly than in our study, by $8.1 \pm 0.5 \mathrm{~kg}$. Ghrelin and leptin concentrations were collected by single specimens (clock time not given) before and after overfeeding. Ghrelin decreased nonsignificantly only, whereas leptin increased (Ravussin et al, 2001). Increases of morning leptin levels were found concomitantly with weight gain during treatment of schizophrenic patients with olanzapine (Kraus et al, 1999) and of depressed patients with mirtazapine (Kraus et al, 2002). In contrast, leptin morning levels remained unchanged in depressed patients during treatment with amitriptyline despite weight gain (Hinze-Selch et al, 2000). The stronger effect in our study compared to the overfeeding of controls (Ravussin et al, 2001) may underline that changes of ghrelin are easier to detect by nocturnal sampling than by single blood samples. Similarly, it appears possible that during the night, changes of leptin occur, which remain hidden in the morning. The decline of nocturnal ghrelin levels after mirtazapine resembles the lower ghrelin morning levels in schizophrenic patients who received stable treatment with risperidone or olanzapine (Togo et al, 2004), whereas it differs from the increase of ghrelin morning concentrations after 6 months of olanzapine treatment in patients with schizophrenia (Murashita et al, 2005). These contrasts show that the role of various drugs, diagnosis, duration of treatment, and time of blood sampling in changes of ghrelin needs to be disentangled. It remains unclear whether the decline in ghrelin in our sample is the mechanism or the consequence of weight gain during mirtazapine administration. Mirtazapine's antagonistic action at histamine $\mathrm{H} 1$ receptors (De Boer, 1995) and attenuation of HPA overactivity are compatible with counteracting loss of appetite and body weight by this drug. Comparative studies should help delineate whether mirtazapine shares its effect on ghrelin with other antidepressants.

A major limitation of our study is the small sample size. However, the previous findings mentioned suggested that mirtazapine exhibits strong effects on neuroendocrinology and sleep parameters. According to our sample size estimation, the number of cases was sufficient to detect effects at a type II error rate of $20 \%$ ( $=80 \%$ power), which is confirmed by our findings. Our study corroborates that mirtazapine is able to counteract a wide range of neurobiological and psychopathological symptoms of depression, including disturbed sleep, hypercortisolism, HPA overdrive as assessed by the DEX-CRH test, low melatonin syndrome, and weight loss. These beneficial effects appear to be mediated by various actions including $5 \mathrm{HT}_{2}$ receptor blockade and action on presynaptic adrenergic alpha 2 receptors, on the HPA system, and on ghrelin and leptin. The profile of actions appears unique and is not shared exactly by any other compound investigated so far.

\section{ACKNOWLEDGEMENTS}

This study was supported by a grant from Organon $\mathrm{GmbH}$, Oberschleissheim, Germany.

\section{REFERENCES}

American Sleep Disorders Association (1992). EEG arousals: scoring rules and examples: a preliminary report from the Sleep Disorders Atlas Task Force of the American Sleep Disorders Association. Sleep 15: 173-184.

Antonijevic IA, Murck H, Frieboes RM, Horn R, Brabant G, Steiger A (1998). Elevated nocturnal profiles of serum leptin in patients with depression. J Psychiatr Res 32: 403-410.

Antonijevic IA, Steiger A (2003). Depression-like changes of the sleep-EEG during high dose corticosteroid treatment in patients with multiple sclerosis. Psychoneuroendocrinology 28: 401-418.

Armitage R (2000). The effects of antidepressants on sleep in patients with depression. Can J Psychiatry Rev Can Psychiatrie 45: 803-809.

Aslan S, Isik E, Cosar B (2002). The effects of mirtazapine on sleep: a placebo controlled, double-blind study in young healthy volunteers. Sleep 25: 677-679. 
Bates SH, Myers MG (2003). The role of leptin receptor signaling in feeding and neuroendocrine function. Trends Endocrinol Metab 14: 447-452.

Bischoff P, Mahlstedt D, Blanc I, Esch OSA (1998). Quantitative topographical electroencephalographic analysis after intravenous clonidine in healthy male volunteers. Anesth Analg 86: 202-207.

Brandenberger G, Luthringer R, Muller G, Gronfier C, Schaltenbrand N, Macher JP et al (1996). 5-HT2 receptors are partially involved in the relationship between renin release and delta relative power. J Endocrinol Invest 19: 556-562.

De Boer T (1995). The effects of mirtazapine on central noradrenergic and serotonergic neurotransmission. Int Clin Psychopharmacol 10: 19-23.

Dijk DJ, Beersma DG, Daan S, Van den Hoofdakker RH (1989). Effects of seganserin, a 5-HT2 antagonist, and temazepam on human sleep stages and EEG power spectra. Eur J Pharmacol 171: 207-218.

Dzaja A, Dalal MA, Himmerich $\mathrm{H}$, Uhr $\mathrm{M}$, Pollmächer $\mathrm{T}$, Schuld A (2004). Sleep enhances nocturnal plasma ghrelin levels in healthy subjects. Am J Physiol Endocrinol Metab 286: E963-E967.

Ehlers CL, Kupfer DJ (1987). Hypothalamic peptide modulation of EEG sleep in depression: a further application of the S-process hypothesis. Biol Psychiatry 22: 513-517.

Emilien G (1990). Effects of clonidine, yohimbine and eserine on the quantified EEG of rats. Arch Int Pharmacodyn Ther 304: $105-124$.

Fawcett J, Barkin RL (1998). Review of the results from clinical studies on the efficacy, safety and tolerability of mirtazapine for the treatment of patients with major depression. J Affect Disord 51: 267-285.

Hamilton M (1960). A rating scale for depression. J Neurol, Neurosurg Psychiatry 23: 56-62.

Hauri P, Hawkins DR (1973). Alpha-delta sleep. Electroencephalogr Clin Neurophysiol 34: 233-237.

Held K, Künzel H, Ising M, Schmid DA, Zobel A, Murck H et al (2004). Treatment with the $\mathrm{CRH}_{1}$-receptor antagonist R121919 improves sleep EEG in patients with depression. J Psychiatr Res 38: $129-136$.

Heuser I, Yassouridis A, Holsboer F (1994). The combined dexamethasone/CRH test: a refined laboratory test for psychiatric disorders. J Psychiatr Res 28: 341-356.

Hinze-Selch D, Schuld A, Kraus T, Kuhn M, Uhr M, Pollmächer T (2000). Effects of antidepressants on weight and on the plasma levels of leptin, TNF-alpha and soluble TNF receptors: a longitudinal study in patients treated with amitriptyline or paroxetine. Neuropsychopharmacology 23: 13-19.

Holm S (1979). A simple sequentially rejective multiple test procedure. Scand J Stat 6: 65-70.

Holsboer F (2000). The corticosteroid receptor hypothesis of depression. Neuropsychopharmacology 23: 477-501.

Holsboer F (2003). High-quality antidepressant discovery by understanding stress hormone physiology. Ann NY Acad Sci 1007: 394-404.

Holsboer F, von Bardeleben U, Steiger A (1988). Effects of intravenous corticotropin-releasing hormone upon sleep-related growth hormone surge and sleep EEG in man. Neuroendocrinology 48: 32-38.

Horvath TL, Diano S, Sotonyi P, Heiman M, Tschöp M (2001). Minireview: ghrelin and the regulation of energy balance-a hypothalamic perspective. Endocrinology 142: 4163-4169.

Idzikowski C, Mills FJ, Glennard R (1986). 5-Hydroxytryptamine-2 antagonist increases human slow wave sleep. Brain Res 378: 164-168.

Kellner M, Yassouridis A, Manz B, Steiger A, Holsboer F, Wiedemann K (1997). Corticotropin-releasing hormone inhibits melatonin secretion in healthy volunteers - a potential link to low-melatonin syndrome in depression? Neuroendocrinology 16: 339-345.
Kerkhofs M, Linkowski P, Mendlewicz J (1989). Effects of intravenous catheter on sleep in healthy men and in depressed patients. Sleep 12: 113-119.

Kojima M, Hosoda H, Date Y, Nakazato M, Matsuo H, Kangawa K (1999). Ghrelin is a growth hormone-releasing acylated peptide from stomach. Nature 402: 656-660.

Kraus T, Haack M, Schuld A, Hinze-Selch D, Koethe D, Pollmächer T (2002). Body weight, the tumor necrosis factor system, and leptin production during treatment with mirtazapine or venlafaxine. Pharmacopsychiatry 35: 220-225.

Kraus T, Haack M, Schuld A, Hinze-Selch D, Kuhn M, Uhr M et al (1999). Body weight and leptin plasma levels during treatment with antipsychotic drugs. Am J Psychiatry 156: 312-314.

Künzel HE, Steiger A, Held K, Antonijevic IA, Frieboes RM, Murck $\mathrm{H}$ (2005). Changes in sleep-electroencephalogram and nocturnal hormone secretion after administration of the antidyskinetic agent sarizotan in healthy young male volunteers. Psychopharmacology 180: 327-332.

Laakmann G, Hennig J, Baghai T, Schüle C (2004). Mirtazapine acutely inhibits salivary cortisol concentrations in depressed patients. Ann NY Acad Sci 1032: 279-282.

Laakmann G, Schüle C, Baghai T, Waldvogel E (1999). Effects of mirtazapine on growth hormone, prolactin and cortisol secretion in healthy male subjects. Psychoneuroendocrinology 24: 769-784.

Linkowski P, Mendlewicz J, Kerkhofs M, Leclercq R, Golstein J, Brasseur M et al (1987). 24-hour profiles of adrenocorticotropin, cortisol, and growth hormone in major depressive illness: effect of antidepressant treatment. J Clin Endocrinol Metab 65: $141-152$

Miles A, Philbrick DR (1988). Melatonin and psychiatry. Biol Psychiatry 23: 405-425.

Montgomery SA, Asberg M (1979). A new depression scale designed to be sensitive to change. Br J Psychiatry 134: 382-389.

Murashita M, Kusumi I, Inoue $\mathrm{T}$, Takahashi $\mathrm{Y}$, Hosoda $\mathrm{H}$, Kangawa $\mathrm{K}$ et al (2005). Olanzapine increases plasma ghrelin level in patients with schizophrenia. Psychoneuroendocrinology 30: $106-110$

Murck H, Frieboes RM, Antonijevic IA, Steiger A (2001). Distinct temporal pattern of the effects of the combined serotoninreuptake inhibitor and 5- $\mathrm{HT}_{1 \mathrm{~A}}$ agonist EMD 68843 on the sleep EEG in healthy men. Psychopharmacology 155: 187-192.

Murck H, Nickel T, Künzel H, Antonijevic IA, Schill J, Zobel A et al (2003). State markers of depression in sleep EEG: dependency on drug and gender in patients treated with tianeptine or paroxetine. Neuropsychopharmacology 28: 348-358.

Nemeroff CB (1996). The corticotropin-releasing factor (CRF) hypothesis of depression: new findings and new directions. Mol Psychiatry 1: 336-342.

Nutt DJ (2002). Tolerability and safety aspects of mirtazapine. Hum Psychopharmacol 17: S37-S41.

Otto B, Cuntz U, Fruehauf E, Wawarta R, Folwaczny C, Riepl RL et al (2001). Weight gain decreases elevated plasma ghrelin concentrations of patients with anorexia nervosa. Eur $J$ Endocrinol 145: R5-R9.

Palazidou E, Papadopoulos A, Sitsen A, Stahl S, Checkley S (1989). An alpha 2 adrenoceptor antagonist, Org 3770, enhances nocturnal melatonin secretion in man. Psychopharmacology 97: 115-117.

Pickworth WB, Sharpe LG, Gupta VN (1982). Morphine-like effects of clonidine on the EEG, slow wave sleep and behavior in the dog. Eur J Pharmacol 81: 551-557.

Pivik RT, Harman K (1995). A reconceptualization of EEG alphaactivity as an index of arousal during sleep - all alpha-activity is not equal. J Sleep Res 4: 131-137.

Ramesh V, Kumar VM (1998). The role of alpha-2 receptors in the medial preoptic area in the regulation of sleep-wakefulness and body temperature. Neuroscience 85: 807-817.

Ravussin E, Tschöp M, Morales S, Bouchard C, Heiman ML (2001). Plasma ghrelin concentration and energy balance: overfeeding 
and negative energy balance studies in twins. J Clin Endocrinol Metab 86: 5972.

Rechtschaffen A, Kales A (1968). A Manual of Standardized Terminology, Techniques and Scoring System for Sleep Stages of Human Subjects. US Department of Health, Education \& Welfare, Neurological Information Network: Bethesda, MD.

Röschke J, Kögel P, Schlösser R, Wagner P, Mann K, Rossbach W et al (1997). Analysis of sleep EEG microstructure in subchronic paroxetine treatment of healthy subjects. Psychopharmacology 132: 44-49.

Rubin RT, Rhodes ME, Czambel RK (2002). Sexual diergism of baseline plasma leptin and leptin suppression by arginine vasopressin in major depressives and matched controls. Psychiatry Res 113: 255-268.

Ruigt GSF, Kemp B, Groenhout CM, Kamphuisen HA (1990). Effect of the antidepressant Org 3770 on human sleep. Eur J Clin Pharmacol 38: 551-554.

Rush AJ, Armitage R, Gillin JC, Yonkers KA, Winokur A, Moldofsky H et al (1998). Comparative effects of nefazodone and fluoxetine on sleep in outpatients with major depressive disorder. Biol Psychiatry 44: 3-14.

Saletu B, Frey R, Krupka M, Anderer P, Grunberger J, See WR (1991). Sleep laboratory studies on the single-dose effects of serotonin reuptake inhibitors paroxetine and fluoxetine on human sleep and awakening qualities. Sleep 14: 439-447.

Schittecatte M, Dumont F, Machowski R, Cornil C, Lavergne F, Wilmotte J (2002a). Effects of mirtazapine on sleep polygraphic variables in major depression. Neuropsychobiology 46: 197-201.

Schittecatte M, Dumont F, Machowski R, Fontaine E, Cornil C, Mendlewicz J et al (2002b). Mirtazapine, but not fluvoxamine, normalizes the blunted REM sleep response to clonidine in depressed patients: implications for subsensitivity of alpha(2)adrenergic receptors in depression. Psychiatry Res 109: 1-8.

Schmid DA, Held K, Ising M, Uhr M, Weikel JC, Steiger A (2005). Ghrelin stimulates appetite, imagination of food, GH, ACTH and cortisol, but does not affect leptin in normal controls. Neuropsychopharmacology 30: 1187-1192.

Schüle C, Baghai T, Bidlingmaier M, Strasburger C, Laakmann G (2002a). Endocrinological effects of mirtazapine in healthy volunteers. Prog Neuro-Psychopharmacol Biol Psychiatry 26: 1253-1261.

Schüle C, Baghai T, Goy J, Bidlingmaier M, Strasburger C, Laakmann G (2002b). The influence of mirtazapine on anterior pituitary hormone secretion in healthy male subjects. Psychopharmacology 163: 95-101.

Schüle C, Baghai T, Zwanzger P, Ella R, Eser D, Padberg F et al (2003). Attenuation of hypothalamic-pituitary-adrenocortical hyperactivity in depressed patients by mirtazapine. Psychopharmacology 166: 271-275.

Seifritz E, Moore P, Trachsel L, Bhatti T, Stahl SM, Gillin JC (1996). The 5- $\mathrm{HT}_{1 \mathrm{~A}}$ agonist ipsapirone enhances EEG slow wave activity in human sleep and produces a power spectrum similar to 5-HT2 blockade. Neurosci Lett 209: 41-44.

Seifritz E, Stahl SM, Gillin JC (1997). Human sleep EEG following the 5-HT1A antagonist pindolol: possible disinhibition of raphe neuron activity. Brain Res 759: 84-91.

Sharp T, Bramwell SR, Hjorth S, Grahame-Smith DG (1989). Pharmacological characterization of 8-OH-DPAT-induced inhibition of rat hippocampal 5-HT release in vivo as measured by microdialysis. Br J Pharmacol 98: 989-997.

Sonntag A, Rothe B, Guldner J, Yassouridis A, Holsboer F, Steiger A (1996). Trimipramine and imipramine exert different effects on the sleep EEG and on nocturnal hormone secretion during treatment of major depression. Depression 4: 1-13.

Spitzer RL, Williams JB, Gibbon M (1987). The structured clinical interview for DSM-III-R: SCID. German version: Wittchen HU, Zaudig M, Schramm E, Spengler P, Mombour W. SKID-Strukturiertes Klinisches Inverview für DSM-III-R. Beltz: Weinheim.
Staner L, Luthringer R, Macher JP (1999). Effects of antidepressant drugs on sleep EEG in patients with major depressionmechanisms and therapeutic implications. CNS Drugs 11: 49-60.

Steiger A (2002). Sleep and the hypothalamo-pituitary-adrenocortical system. Sleep Med Rev 6: 125-138.

Steiger A (2003). Sleep and endocrine regulation. Front Biosci 8(The Basic Science of Sleep): 358-376.

Steiger A, von Bardeleben U, Guldner J, Lauer C, Rothe B, Holsboer F (1993). The sleep EEG and nocturnal hormonal secretion. Studies on changes during the course of depression and on effects of CNS-active drugs. Prog Neuro-Psychopharmacol Biol Psychiatry 17: 125-137.

Steiger A, von Bardeleben U, Herth T, Holsboer F (1989). Sleep EEG and nocturnal secretion of cortisol and growth hormone in male patients with endogenous depression before treatment and after recovery. J Affect Disord 16: 189-195.

Thase ME (1999). Antidepressant treatment of the depressed patient with insomnia. J Clin Psychiatry 60(Suppl 17): 28-31.

Togo T, Hasegawa K, Miura S, Hosojima H, Kojima K, Shoji M et al (2004). Serum ghrelin concentrations in patients receiving olanzapine or risperidone. Psychopharmacology 172: 230-232.

Tschöp M, Smiley DL, Heiman ML (2000). Ghrelin induces adiposity in rodents. Nature 407: 908-913.

Van Bemmel AL, Beersma DG, Van den Hoofdakker RH (1995). Changes in EEG power density of non-REM sleep in depressed patients during treatment with trazodone. J Affect Disord 35: 11-19.

Van Bemmel AL, Vermeeren MT, Ruigt G, Sennef C (1999). The acute effects of the noradrenaline reuptake inhibitor Org 4428 on EEG sleep in healthy volunteers. Neuropsychobiology 40: $107-114$.

Van Cauter E, Latta F, Nedeltcheva A, Spiegel K, Leproult R, Vandenbril C et al (2004). Reciprocal interactions between the GH axis and sleep. Growth Horm IGF Res 14(Suppl A): S10-S17.

Vgontzas AN, Bixler EO, Wittman AM, Zachman K, Lin HM, Vela-Bueno A et al (2001). Middle-aged men show higher sensitivity of sleep to the arousing effects of corticotropinreleasing hormone than young men: clinical implications. J Clin Endocrinol Metab 86: 1489-1495.

Vitiello MV, Larsen LH, Moe KE, Borson S, Schwartz RS, Prinz PN (1996). Objective sleep quality of healthy older men and women is differentially disrupted by nighttime periodic blood sampling via indwelling catheter. Sleep 19: 304-311.

Winokur A, DeMartinis III NA, McNally DP, Gary EM, Cormier JL, Gary KA (2003). Comparative effects of mirtazapine and fluoxetine on sleep physiology measures in patients with major depression and insomnia. J Clin Psychiatry 64: 1224-1229.

Winokur A, Sateia MJ, Hayes JB, Bayles-Dazet W, MacDonald MM, Gary KA (2000). Acute effects of mirtazapine on sleep continuity and sleep architecture in depressed patients: a pilot study. Biol Psychiatry 48: 75-78.

World Health Organization (1993). Mental and Behavioural Disorders. Diagnostic Criteria for research Tenth revision of the International Classification of Diseases. World Health Organization: Geneva.

Wren AM, Seal LJ, Cohen MA, Brynes AE, Frost GS, Murphy KG et al (2001a). Ghrelin enhances appetite and increases food intake in humans. J Clin Endocrinol Metab 86: 5992-5995.

Wren AM, Small CJ, Abbott CR, Dhillo WS, Seal LJ, Cohen MA et al (2001b). Ghrelin causes hyperphagia and obesity in rats. Diabetes 50: 2540-2547.

Yamadera H, Ferber G, Matejcek M, Pokorny R (1985). Electroencephalographic and psychometric assessment of the CNS effects of single doses of guanfacine hydrochloride (Estulic) and clonidine (Catapres). Neuropsychobiology 14: 97-107.

Yeh KC, Kwan KC (1978). Comparison of numerical integrating algorithms by trapezoidal, Lagrange, and spline approximation. J Pharmacokinet Biopharm 6: 79-98. 